\title{
Rapid and sensitive detection of Plesiomonas shigelloides by cross-priming amplification of the $h u g A$ gene
}

\author{
SHUANG MENG, YI WANG, YAN WANG and CHANGYUN YE \\ State Key Laboratory of Infectious Disease Prevention and Control, \\ National Institute for Communicable Disease Control and Prevention, \\ Collaborative Innovation Center for Diagnosis and Treatment of Infectious Diseases, \\ Chinese Center for Disease Control and Prevention, Beijing 102206, P.R. China
}

Received August 19, 2015; Accepted September 2, 2016

DOI: $10.3892 / \mathrm{mmr} .2016 .5937$

\begin{abstract}
Plesiomonas shigelloides (P. shigelloides) is implicated as an aetiological agent of human gastroenteritis in humans, for which reliable laboratory detection of $P$. shigelloides is clinically and epidemiologically desirable. A simple molecular method for rapid detection of $P$. shigelloides using cross-priming amplification (CPA) has been developed, with $h u g A$ as the target. The $h u g A$ gene is required for haem iron utilisation and is critical for the survival and growth of $P$. shigelloides. The assay output was visualised as a colour change with no need to open the reaction tubes, and no false-positive results were detected for the 33 non- $P$. shigelloides strains examined to assess assay specificity. The limit of detection was $200 \mathrm{fg} P$. shigelloides DNA per reaction and $3 \times 10^{3}$ CFU per $\mathrm{g}$ in human stools, which was 100 and 10-fold more sensitive than polymerase chain reaction, respectively. The CPA method was used to detect the presence of $P$. shigelloides in stool specimens from 70 patients with diarrhoea and 30 environmental water samples, with no difference in accuracy between the CPA assay and the biological culture. The present study, therefore, suggests that the $P$. shigelloides hugA CPA assay may represent a valuable tool for rapid and sensitive detection of $P$. shigelloides in primary care facilities and clinical laboratories.
\end{abstract}

\section{Introduction}

Plesiomonas shigelloides ( $P$. shigelloides) is the only species member of the Plesiomonas genus, and the only

Correspondence to: Professor Changyun Ye, State Key Laboratory of Infectious Disease Prevention and Control, National Institute for Communicable Disease Control and Prevention, Collaborative Innovation Center for Diagnosis and Treatment of Infectious Diseases, Chinese Center for Disease Control and Prevention, 155 Changbai Road, Beijing 102206, P.R. China

E-mail: yechangyun@icdc.cn

Key words: Plesiomonas shigelloides, detection, cross-priming amplification, polymerase chain reaction, $h u g A$ gene amplification oxidase-positive member of the Enterobacteriaceae family (1). $P$. shigelloides is present worldwide, primarily in aquatic environments, including freshwater, estuarine and marine environments (2-4). P. shigelloides induces various types of gastroenteritis, including acute secretory gastroenteritis, invasive shigellosis-like disease and cholera-like illness, infections increasing in recent years (5-7).

In humans, although extra-intestinal diseases of $P$. shigelloides are rare, it has been associated with secondary infections in immunocompromised states, including malignancy, blood disorders and hepatobiliary disease (8-10). P. shigelloides may often be missed in stool samples due to its small colony size and relatively low prevalence in gastrointestinal samples. The lack of a routine assay for $P$. shigelloides in cases of gastroenteritis means that this bacterium is identified only occasionally (11). Xia et al (12) reported a case of meningoencephalitis caused by $P$. shigelloides with a fatal outcome in a Chinese neonate. Therefore, its earlier and accurate identification, and the prescription of the correct antibiotic therapy may be critical for patient prognosis.

The traditional culture-based approaches for detection of $P$. shigelloides involve enrichment in liquid media and isolation of colonies on selective media. Although extensively used, these assays are time-consuming and laborious, taking more than three days. In addition, the isolates of $P$. shigelloides appear as green colonies on Hektoen enteric agar, with an appearance similar to that of Shigella (13).

Molecular-based techniques, including polymerase chain reaction (PCR) and quantitative PCR assays, have been established for the detection of $P$. shigelloides, producing reliable results. However, PCR-based techniques rely on expensive thermal cycler or complex sample-handling procedures, limiting its application (14). Therefore, there is an urgent requirement to devise a novel strategy for rapid, robust and sensitive identification of $P$. shigelloides using simple equipment.

Loop-mediated isothermal amplification (LAMP), as a rapid, specific and sensitive detection methodology, has been used to detect various pathogens, including parasites, fungi, bacteria and viruses (15). However, primer design for LAMP techniques is complicated, requiring a specific, long, highly conserved fragment. This limits the application of LAMP for the detection of pathogens (16). A novel technology, cross-priming 
amplification (CPA), overcomes the technical difficulties posed by current LAMP approaches, which contains five specially designed primers (1s, 2a, 3a, 4s and 5a) that recognise five conserved regions on the target sequence. Each cross primer contains 5 ' tail sequences identical to each other's priming site and thus introduces additional priming sites in each round of extension. The primers are designed to accomplish the basic goal of isothermal generation of single-stranded DNA (ssDNA) using a strand-displacing polymerase such as Bst, and the DNA target sequence may be amplified without an initial denaturation step or addition of a nicking enzyme (17-20). The CPA products may be detected by an increase in turbidity, agarose gel electrophoresis of amplicons or by visualization of a colour alteration in the presence of Loopamp ${ }^{\circledR}$ Fluorescent Detection Reagent.

Several potential virulence factors of $P$. shigelloides have been described, however, the pathogenesis of $P$. shigelloides-associated gastroenteritis remains to be elucidated $(21,22)$. Acquisition of iron has been demonstrated to be involved in the virulence of a variety of bacterial pathogens $(23,24)$. Heme is the primary source of iron within the body, and numerous pathogenic bacteria carry heme transport systems (25). The strains of $P$. shigelloides express highly specific outer membrane receptors that bind, extract and transport heme into the bacterial periplasm (26). The hugA genes (heme iron utilization locuaccession no. AY008342.1) encoding the heme iron utilization system of P. shigelloides have been isolated and characterized, and are essential for the growth of P. shigelloides.

The present study aimed to develop a rapid, cost-effective and efficient CPA method for detecting P. shigelloides, and evaluating the assay performance with pathogen-simulated human stool. In addition, the CPA method was compared with PCR to determine the sensitivity and evaluate the practical application in clinical samples.

\section{Materials and methods}

Ethics statement. Stool specimens were acquired from 70 patients with diarrhoea, aged from 18 to 50 years old, and written informed consent was obtained from all participants. The study was reviewed and approved by the ethics committee of the National Institute for Communicable Disease Control and Prevention, Chinese Center for Disease Control and Prevention (Beijing, China), according to the medical research regulations of the Ministry of Health (Beijing, China; approval no. ICDC-2014003).

Bacterial strains. A total of 53 strains (20 P.shigelloides strains and 33 non-P. shigelloides strains, listed in Table I) were used for specificity testing. The bacterial load of the strains used for specificity evaluation was $10^{5} \mathrm{pg} / \mathrm{ml}$, which is high enough to prevent false-negative amplifications. P. shigelloides ATCC 51903 (GenBank accession number AY008342.1) was selected as the positive control for the assay optimisation, sensitivity evaluation, and to spike human stool samples. All strains were cultured overnight at $37^{\circ} \mathrm{C}$ on brain heart infusion (BHI) agar (BD Biosciences, Franklin Lakes, NJ, USA).

Genomic DNA extraction. Bacterial genomic DNA was extracted from all cultured strains using DNA extraction kits
(QIAamp DNA minikitQiagen, Hilden, Germany) according to the manufacturer's instructions.

P. shigelloides hugA CPA primers and reaction conditions. A set of five primers was manually designed to target the nucleotide sequence of $P$. shigelloides ATCC 51903, based on the mechanism of CPA (27). The sequences and locations of the primers within hugA are presented in Table II and Fig. 1. CPA reactions were performed using the Loopamp kit (Eiken Chemical Co., Ltd., Tokyo, Japan) in a final volume of $20 \mu \mathrm{l}$ containing $2.4 \mathrm{mM}$ cross primer As, $1.44 \mathrm{mM}$ each of primers $2 \mathrm{a}$ and $3 \mathrm{a}, 0.3 \mathrm{mM}$ each of displacement primers $4 \mathrm{~s}$ and $5 \mathrm{a}$, $20 \mathrm{mM}$ Tris- $\mathrm{HCl}$ (pH 8.8), $10 \mathrm{mM} \mathrm{KCl}, 4 \mathrm{mM} \mathrm{MgSO}_{4}, 10 \mathrm{mM}$ $\left(\mathrm{NH}_{4}\right)_{2} \mathrm{SO}_{4}, 0.1 \%$ Tween $20,0.8 \mathrm{M}$ betaine, $1.4 \mathrm{mM}$ deoxynucleoside triphosphates (dNTPs), $1 \mu \mathrm{l}$ of $B s t$ DNA polymerase

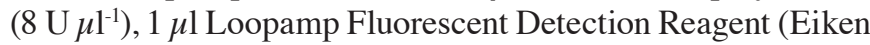
Chemical Co., Ltd.) and $1 \mu 1$ DNA template. The reaction mixture was incubated in an LA320 Real-Time Turbidimeter (Teramecs Co., Ltd., Kyoto, Japan) at $63^{\circ} \mathrm{C}$ for $60 \mathrm{~min}$, and then heated at $95^{\circ} \mathrm{C}$ for $5 \mathrm{~min}$ to terminate the reaction. Amplified products were directly detected by observing a colour change from orange to green by the naked eye, or by electrophoresis on $2 \%$ agarose gels using staining with GoldenView reagent. Furthermore, real-time monitoring of the CPA reaction was performed by recording the optical density at $650 \mathrm{~nm}$ every $6 \mathrm{sec}$ using the LA-320C Real-Time Turbidimeter. A positive reaction was defined as a turbidity cut-off value of $>0.1$ within $60 \mathrm{~min}$.

Evaluation of the specificity, sensitivity and reproducibility of the P. shigelloides hugA CPA assay. To determine the specificity of the CPA assay, the CPA reaction was performed under the conditions described above with DNA templates from 20 P. shigelloides and 33 non- $P$. shigelloides strains (Table I). All detection assays were performed in triplicate.

To assess the analytical sensitivity of CPA assay, CPA assays were performed using serial dilutions (20, $2 \mathrm{ng}, 200$, 20, $2 \mathrm{pg}, 200,100$ and $50 \mathrm{fg}$ per $\mu \mathrm{l}$ ) of $P$. shigelloides genomic DNA. The genomic templates $(1 \mu \mathrm{l})$ were added into the CPA mixture and at least 3 replicates of each dilution were assessed to define the limit of detection ( $\mathrm{LoD}$ ) of the CPA approach. Mixtures without DNA templates served as a negative control. The sensitivity of the CPA assay on P. shigelloides was determined by analyzing the amplifications produced from the serial dilutions of the P. shigelloides genomic DNA.

To compare the sensitivities of the CPA and PCR assay in pure culture, template DNA from P. shigelloides (ATCC 51903) was serially diluted $(20,2.0 \mathrm{ng}, 200,20,2.0 \mathrm{pg}, 200 \mathrm{fg}, 100$ and $50 \mathrm{fg}$ per $\mu \mathrm{l})$. The LoD of CPA and PCR was ascertained using the two assays.

To evaluate the reproducibility of the CPA assay, different concentrations (20 ng, 200 and $2.0 \mathrm{pg}$ ) of template DNA from $P$. shigelloides (ATCC 51903) were amplified two ways (10 times on one day and once each on 10 different days). The intra-assay and inter-assay variation were analysed at the time of precipitation, as measured by turbidity on the Real-Time Turbidimeter. The coefficient of variation (CV) is equal to the standard deviation (SD) divided by the mean average, multiplied by 100. Statistical analyses were conducted using SPSS software (version, 19.0; IBM SPSS, Armonk, NY, USA). 
Table I. Bacterial strains used in the present study.

\begin{tabular}{|c|c|c|}
\hline Latin name & Strain no. (source of strain) & No. of strains \\
\hline \multirow[t]{2}{*}{ Plesiomonas shigelloides } & ATCC 51903 & 1 \\
\hline & Isolated strains (ICDC) & 19 \\
\hline Enteropathogenic Escherichia coli & Isolated strain (ICDC) & 1 \\
\hline Enterotoxigenic Escherichia coli & Isolated strain (ICDC) & 1 \\
\hline Enteroinvasive Escherichia coli & Isolated strain (ICDC) & 1 \\
\hline Enterohaemorrhagic Escherichia coli & EDL 933 (isolated previously in our laboratory) & 1 \\
\hline Enteroaggregative Escherichia coli & Isolated strain (ICDC) & 1 \\
\hline Salmonella enterica & ATCC 14028 & 1 \\
\hline Shigella flexneri & Isolated strain (ICDC) & 1 \\
\hline Shigella sonnei & ATCC 25931 & 1 \\
\hline Proteus vulgaris & Isolated strain (ICDC) & 1 \\
\hline Aeromonas veronii & ATCC 35622 & 1 \\
\hline Aeromonas salmonicida & ATCC 7965 & 1 \\
\hline Aeromonas caviae & ATCC 15468 & 1 \\
\hline Aeromonas media & ATCC 33907 & 1 \\
\hline Clostridium perfringens & Isolated strain (ICDC) & 1 \\
\hline Enterobacter cloacae & Isolated strain (ICDC) & 1 \\
\hline Serratia marcescens & Isolated strain (ICDC) & 1 \\
\hline Vibrio parahaemolyticus & ATCC 17802 & 1 \\
\hline Staphylococcus aureus & ATCC 6538 & 1 \\
\hline Streptococcus pneumoniae & Isolated strain (ICDC) & 1 \\
\hline Streptococcus pyogenes & Isolated strain (ICDC) & 1 \\
\hline Streptococcus sanguis & Isolated strain (ICDC) & 1 \\
\hline Streptococcus salivarius & Isolated strain (ICDC) & 1 \\
\hline Streptococcus bovis & Isolated strain (ICDC) & 1 \\
\hline Enterococcus faecalis & ATCC 35667 & 1 \\
\hline Yersinia enterocolitica & ATCC 23715 & 1 \\
\hline Pseudomonas aeruginosa & ATCC 15442 & 1 \\
\hline Aeromonas hydrophila & ATCC 7966 & 1 \\
\hline Listeria monocytogenes & ATCC 54003 & 2 \\
\hline Enterobacter sakazakii & ATCC 51329 & 1 \\
\hline Campylobacter jejuni & ATCC 33291 & 1 \\
\hline Vibrio minicus & Isolated strain (ICDC) & 1 \\
\hline Vibrio vulnificus & Isolated strain (ICDC) & 1 \\
\hline
\end{tabular}

ATCC, American type culture collection; ICDC, national institute for communicable disease control and prevention, Chinese center for disease control and prevention.

PCR amplifications were performed in a final volume of $20 \mu \mathrm{l}$ containing $50 \mathrm{mM} \mathrm{KCl}, 10 \mathrm{mM}$ Tris- $\mathrm{HCl}$ (pH 8.3), $0.001 \%$ gelatin, $1.5 \mathrm{mM} \mathrm{MgCl} 2,0.2 \mu \mathrm{M}$ each of hugA forward and hugA reverse primers, $0.2 \mathrm{mM}$ each of dNTPs, 0.5 units of Ex Taq DNA polymerase (Takara Bio, Inc., Otsu, Japan) and $1 \mu \mathrm{l}$ DNA template. The program consisted of an initial denaturation step of $5 \mathrm{~min}$ at $95^{\circ} \mathrm{C}, 35$ cycles of $30 \mathrm{sec}$ at $95^{\circ} \mathrm{C}, 30 \mathrm{sec}$ at $60^{\circ} \mathrm{C}$, and $30 \mathrm{sec}$ at $72^{\circ} \mathrm{C}$, and a final $5 \mathrm{~min}$ extension at $72^{\circ} \mathrm{C}$. The PCR products were visualised by $2 \%$ agarose gel electrophoresis to verify the presence of the expected 435-bp fragment.

P. shigelloides hugA CPA application in simulated human stools specimens. Human stool specimens were obtained from a healthy donor with the written informed consent. The human stool specimens were confirmed to be $P$. shigelloides-negative using a traditional culture assay and PCR amplification (Table III). To determine the LoD of CPA in human stool, 10-fold serial dilutions of a mid-log phase culture of $P$. shigelloides grown in BHI broth at $37^{\circ} \mathrm{C}$ were prepared in PBS, quantified using the standard plating method, and added to the stool samples at $3 \times 10^{1}-3 \times 10^{6} \mathrm{CFU} / \mathrm{g}$. Aliquots $(0.2 \mathrm{~g})$ of the stools were used for DNA extraction with a QIAamp DNA Mini kit. This experiment was performed in triplicate independently, and the supernatants $(2 \mu \mathrm{l})$ were used for CPA and PCR.

Practical application of the P. shigelloides hugA CPA assay. To estimate the feasibility of the CPA assay to detect $P$. shigelloides in clinical samples, 100 samples (70 stool specimens 
Table II. CPA and PCR primers used to detect Plesiomonas shigelloides.

\begin{tabular}{|c|c|c|c|}
\hline Assay type & Primer/probe name & Sequence $\left(5^{\prime}-3^{\prime}\right)$ & Length (nt) \\
\hline \multirow[t]{5}{*}{ hugA-CРA } & AS $(2 a+1 s)$ & $\begin{array}{l}\text { AAGCCAATCCCGATTTGAAACCTTTTG } \\
\text { TTAAAGCGCATCTGAGCTGAG }\end{array}$ & 48 \\
\hline & $3 a$ & GGAGACCGCCAAAAACAAAGAGAT & 24 \\
\hline & $2 \mathrm{a}$ & AAGCCAATCCCGATTTGAAACC & 22 \\
\hline & $4 s$ & GTCGCCCCAAACGCTAACTC & 20 \\
\hline & $5 a$ & CGATGGGCTGCAACGTGTT & 19 \\
\hline \multirow[t]{2}{*}{ hugA-PCR } & $\mathrm{F}$ & GCGAGCGGGAAGGGAAGAACC & 21 \\
\hline & $\mathrm{R}$ & GTCGCCCCAAACGCTAACTCATCA & 24 \\
\hline
\end{tabular}

CPA, cross-priming amplification; PCR, polymerase chain reaction; F, forward; R, reverse.

Table III. Reproducibility of the Plesiomonas shigelloides hugA cross-priming amplification assay.

\begin{tabular}{|c|c|c|c|c|c|}
\hline Reproducibility & $\begin{array}{c}\text { Template DNA } \\
\text { (pg/reaction) }\end{array}$ & $\begin{array}{l}\text { Number of } \\
\text { detections }\end{array}$ & $\begin{array}{c}\text { Mean time of } \\
\text { precipitation (mins) }\end{array}$ & $\begin{array}{l}\text { Standard } \\
\text { deviation }\end{array}$ & $\begin{array}{l}\text { Coefficient of } \\
\text { variation }(\%)\end{array}$ \\
\hline \multirow[t]{3}{*}{ Intra-assay } & $2 \times 10^{4}$ & 10 & 23.4 & 0.21 & 0.90 \\
\hline & $2 \times 10^{2}$ & 10 & 27.3 & 0.37 & 1.36 \\
\hline & 2 & 10 & 38.4 & 0.49 & 1.28 \\
\hline \multirow[t]{3}{*}{ Inter-assay } & $2 \times 10^{4}$ & 10 & 23.3 & 0.23 & 0.99 \\
\hline & $2 \times 10^{2}$ & 10 & 27.5 & 0.33 & 1.20 \\
\hline & 2 & 10 & 38.7 & 0.66 & 1.71 \\
\hline
\end{tabular}

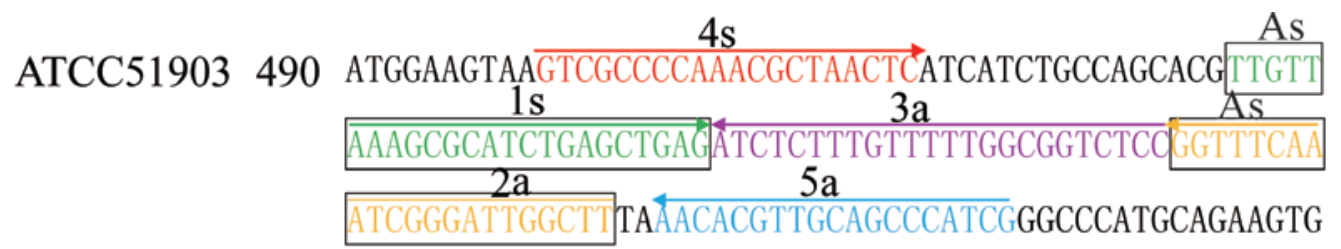

Figure 1. Target sequence and primer locations. Nucleotide sequence of the hugA gene fragment from Plesiomonas shigelloides ATCC 51903 used to design the cross-priming amplification primers. The locations of primers within the hugA gene are shown as right and left arrows indicating whether the sense or complementary sequence was used.

from patients with diarrhoea and 30 water samples from the environment) were analysed using the CPA method, and compared with the results from the traditional culture and PCR methods. Culture-based detection of stool samples was performed by enriching $2 \mathrm{~g}$ stool specimens in $20 \mathrm{ml}$ tetrathionate broth without iodine (Oxoid; Thermo Fisher Scientific, Inc., Waltham, MA, USA) for $10 \mathrm{~h}$ at $37^{\circ} \mathrm{C}$, and then streaking on inositol brilliant green bile salts (IBB) agar (Oxoid; Thermo Fisher Scientific, Inc.) and the plates incubated at $35^{\circ} \mathrm{C}$ for 24 h. Pink colonies suspected to be $P$. shigelloides were Gram stained, picked onto BHI agar at $37^{\circ} \mathrm{C}$ for $18 \mathrm{~h}$ and subjected to biochemical tests using the API 20E system (BioMérieux, Marcy-l'Étoile, France) (25).

Water samples $(500 \mathrm{ml})$ were filtered through sterile analytical filters (NalgenThermo Fisher Scientific, Inc.) with pore sizes of $0.45 \mu \mathrm{m}$, within $30 \mathrm{~h}$ of sample collection. The filters were enriched in $20 \mathrm{ml}$ tetrathionate broth without iodine for $10 \mathrm{~h}$ at $37^{\circ} \mathrm{C}$, streaked on IBB agar and the plates were incubated at $35^{\circ} \mathrm{C}$ for $24 \mathrm{~h}$ (25). Pink colonies suspected to be $P$. shigelloides were Gram stained, picked onto BHI agar at $37^{\circ} \mathrm{C}$ for $18 \mathrm{~h}$ and subjected to biochemical tests using the API 20E system.

DNA was extracted from $1 \mathrm{ml}$ aliquots of the enrichment broth using the QIAamp DNA Mini kit, and $2 \mu 1$ of each DNA extract was used as the template in the CPA and PCR assays. P. shigelloides (ATCC 51903) genomic DNA was used as the positive control template, and sterile water was used as the negative control template.

\section{Results}

Primer design for the P. shigelloides hugA CPA assay. For the $P$. shigelloides-specific hugA gene, a set of 5 primers, which targeted 5 distinct regions, was designed for the CPA assay by sequence alignment and primer software Primer Premier 5.0 
(Premier Biosoft International, Palo Alto, CA, USA). These included the amplification primer $2 \mathrm{a}$ and $1 \mathrm{~s}$, designated as the cross primer (As) and two amplification primers (3a and 2a). The specificity of the CPA primers was confirmed using the NCBI Basic Local Alignment Search Tool (National Institutes of Health, Bethesda, MD, USA). The details of the primers are presented in Table II and Fig. 1.

Confirmation and detection of $P$. shigelloides CPA products. The amplification products were examined by visual inspection using Loopamp Fluorescent Detection Reagent and the positive amplifications were directly observed due to the colour change from the original orange to green (Fig. 2A). In addition, the conventional CPA products were assessed by $2 \%$ agarose gel electrophoresis, and positive results demonstrated a typical ladder-like pattern (Fig. 2B).

Specificity of the P. shigelloides hugA CPA assay. The specificity of the CPA assay towards the $P$. shigelloides hugA gene was examined by performing the assay with DNA from 53 bacterial strains from 29 different species as the template (Table I). The $20 P$. shigelloides strains were correctly identified, whereas no amplification was observed in the 33 non-P. shigelloides strains. The results demonstrated that the specificity of the CPA assay was $100 \%$, and the sequence revealed no cross-reaction with different pathogens.

Sensitivity of the P. shigelloides hugA CPA assay. The sensitivity of CPA assay towards $P$. shigelloides was examined by determining the LoD of reactions performed with serial dilutions of $P$. shigelloides genomic DNA (20, $2 \mathrm{ng}, 200,20,2 \mathrm{pg}$, 200, 100 and $50 \mathrm{fg}$ per $\mu \mathrm{l}$ ). The LoD of CPA (Fig. 3A) was $200 \mathrm{fg}$ DNA/tube, whereas the LoD of PCR assay was $20 \mathrm{pg}$ DNA/tube (Fig. 3B). These results indicated that the CPA assay was 100 -fold more sensitive than the PCR assay for detecting $P$. shigelloides genomic DNA.

Reproducibility of the P. shigelloides hugA CPA assay. The intra-assay coefficient of variation $(\mathrm{CV})$ was determined using various quantities of template DNA (20 ng, 200 and $2.0 \mathrm{pg}$ ) 10 times in a single run. The inter-assay CV was determined by performing the CPA assay using the same templates in 10 separate runs. The intra-assay CV ranged from 0.9 to $1.36 \%$, and the inter-assay $\mathrm{CV}$ ranged from 0.99 to $1.71 \%$ (Table III). The reproducibility of the $P$. shigelloides hugA CPA assay was, therefore, good.

P. shigelloides hugA CPA efficacy in human stool specimens. The LoD of the P. shigelloides hugA CPA assay on human stools containing measured concentrations of $P$. shigelloides was examined. The CPA assay identified the presence of $P$. shigelloides in stools containing as little as $3 \times 10^{3} \mathrm{CFU}$ per $\mathrm{g}$ stool (Fig. 4A), whereas PCR had a LoD of $3 \times 10^{4} \mathrm{CFU} / \mathrm{g}$ stool (Fig. 4B).

Utility of the P. shigelloides hugA CPA assay for detection in clinical and environmental samples. The $P$. shigelloides hugA CPA assay, PCR and culture-based detection were used to detect $P$. shigelloides in 100 clinical and environmental specimens (70 stool samples from patients with diarrhoea and
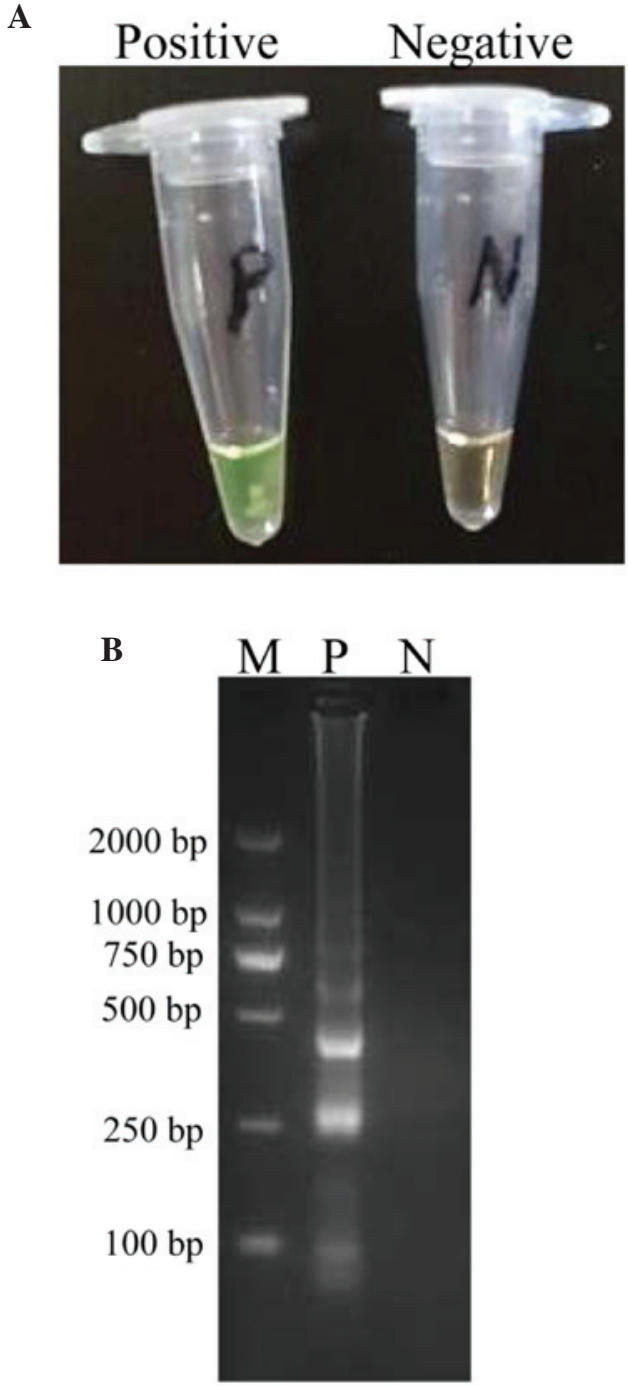

Figure 2. Confirmation and detection of the CPA products. (A) A colour change from orange to green in the presence of Loopamp Fluorescent Detection Agent indicated a positive CPA reaction, whereas retention of the orange colour of the reagent indicated a negative reaction. (B) Separation of positive and negative CPA reactions by electrophoresis on $2 \%$ agarose gels. CPA, cross-priming amplification; M, DL 2,000 bp DNA marke; P, positive CPA product; $\mathrm{N}$, negative control.

30 environmental water samples). The $P$. shigelloides hugA CPA assay and PCR method detected $P$. shigelloides in 11 (15.7\%) and $8(11.4 \%)$ stool specimens, respectively (Table IV). In the case of water samples, 4 (13.3\%) and 3 (10.0\%) water samples were $P$. shigelloides positive by CPA and PCR, respectively (Table IV). The samples that were positive by PCR were also positive by CPA. P. shigelloides strains were successfully isolated from all the CPA positive samples. The CPA detection accuracy was $100 \%$ compared with the traditional culture method. All samples were subjected to culture-based detection. The $P$. shigelloides hugA CPA assay, therefore, appears to be more sensitive for the detection of $P$. shigelloides in clinical and environmental samples than conventional PCR.

\section{Discussion}

In the present study, a CPA assay was developed for the rapid detection of $P$. shigelloides as a potential on-site and 



Figure 3. Sensitivity of the CPA and PCR methods. (A) Sensitivity of the CPA assay was assessed by measuring the turbidity (optical density at $650 \mathrm{~nm}$ ) of reactions over the course of $60 \mathrm{~min}$, using serial dilutions of Plesiomonas shigelloides ATCC 51903 genomic DNA as template (1, $20 \mathrm{ng} ; 2,2 \mathrm{ng} ; 3,200 \mathrm{pg}$; 4, $20 \mathrm{pg} ; 5,2 \mathrm{pg}$; and 6, $200 \mathrm{fg}$ per $\mu 1$, respectively). A turbidity value of $>0.1$ within 60 min indicated a positive reaction. (B) Sensitivity of the PCR method was evaluated by detection of a 435-bp single target band by agarose gel electrophoresis, using serial dilutions of Plesiomonas shigelloides ATCC 51903 genomic DNA as template (1, $20 \mathrm{ng} ; 2,2 \mathrm{ng} ; 3,200 \mathrm{pg}$; 4, $20 \mathrm{pg} ; 5,2 \mathrm{pg} ; 6$, $200 \mathrm{fg} ; 7,100 \mathrm{fg}$; and 8, 50 fg per $\mu \mathrm{l})$. CPA, cross-priming amplification; PCR, polymerase chain reaction; M, DL 2,000 bp DNA marker.

point-of-care test in clinics. P. shigelloides is an important pathogen, which may contaminate food or aquatic environment and causes gastrointestinal illness (6-8). However, the current lack of a rapid and sensitive diagnostic method can result in inappropriate antimicrobial therapies being administered, potentially leading to further complications and fatal outcomes $(12,28)$. Therefore, a rapid, sensitive, specific and economical detection method is urgently required.

The conventional methods for the isolation and identification of $P$. shigelloides involve enrichment in fluid media and subsequent isolation of colonies on selective media. Although extensively performed, the methods are labor-intensive and time-consuming, making it unsuitable for the rapid detection of causative pathogens associated with sporadic and outbreaks cases (25). As an alternative, various PCR-based assays have been developed for the detection of $P$. shigelloides. However, PCR-based methods require a high-precision thermal cycler, which restricts their widespread application and mean that these techniques are not suited to diagnosis of $P$. shigelloides in basic clinical and field laboratories in rural areas. Several isothermal amplification methods have been developed for the rapid diagnosis of infectious pathogens, including LAMP, which is a promising low-cost method for detecting various infectious pathogens (17-20). To date, the LAMP technique has been used to detect $P$. shigelloides in stool and environment specimens.
Table IV. Practical application of the Plesiomonas shigelloides hugA cross-priming amplification assay.

\begin{tabular}{lccccc}
\hline & $\begin{array}{c}\text { Diarrhoea patient } \\
\text { specimens }(\mathrm{n}=70)\end{array}$ & & \multicolumn{2}{c}{$\begin{array}{c}\text { Environmental water } \\
\text { samples }(\mathrm{n}=30)\end{array}$} \\
\cline { 2 - 3 } \cline { 5 - 6 } $\begin{array}{l}\text { Detection } \\
\text { method }\end{array}$ & Positive & Negative & & Positive & Negative \\
\hline $\begin{array}{l}\text { Polymerase } \\
\text { chain reaction }\end{array}$ & 8 & 62 & & 3 & 27 \\
$\begin{array}{l}\text { Culture } \\
\begin{array}{l}\text { Cross-priming } \\
\text { amplification }\end{array}\end{array}$ & 11 & 59 & & 4 & 26 \\
\hline
\end{tabular}

$\mathbf{A}$



B

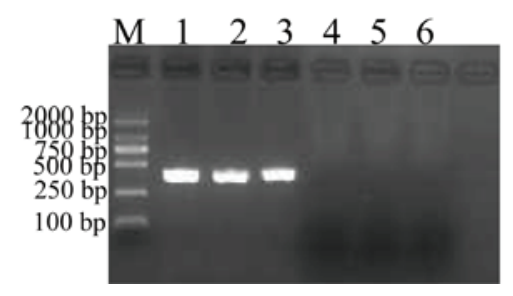

Figure 4. The detection limit of the CPA and PCR in spiked human stool. Stools from a healthy volunteer were spiked with (1) $3 \times 10^{6}$, (2) $3 \times 10^{5}$, (3) $3 \times 10^{4}$, (4) $3 \times 10^{3}$, (5) $3 \times 10^{2}$ and (6) $3 \times 10^{1}$ CFU P. shigelloides per g stool, prior to DNA extraction. (A) Detection by CPA and measurement of the turbidity (optical density at $650 \mathrm{~nm}$ ) of reactions over the course of $60 \mathrm{~min}$. A turbidity value of $>0.1$ within $60 \mathrm{~min}$ indicated a positive reaction. (B) Detection by PCR and agarose gel electrophoresis. CPA, cross-priming amplification; $\mathrm{PCR}$, polymerase chain reaction; $\mathrm{M}$, DL 2,000 bp DNA marker.

However, LAMP assays require primers with high stringency, for which primer design is complicated and requires specific software (Primer Explorer V4 softwarEiken Chemical Co. Ltd.), therefore, posing an obstacle for clinical application (16). Moreover, in LAMP, an additional step of DNA template denaturation is required (29). The CPA assay reported in the study does not require a denaturation step, does not require specific software for primer design, and as the gene target sequence used for primer design in the P. shigelloides hugA CPA assay is shorter than required for the LAMP assay, the subsequently reduced detection time is conducive to clinical application, as 
described by Fang et al (30) for the detection of M.tuberculosis in sputum samples. CPA is a powerful innovative gene amplification technique, which has been described as an easy and rapid diagnostic tool for the detection of pathogens (27). The equipment requirements for the CPA assay are also limited to a heat block or water bath, maintaining a constant temperature of $63^{\circ} \mathrm{C}$ for $1 \mathrm{~h}$. The measurement of CPA products is possible by measuring turbidity, electrophoresis of amplicons or visual observation when using the Loopamp Fluorescent Detection Reagent. These features establish the CPA assay as a suitable method for P. shigelloides detection in basic clinical and field laboratories.

A 128-nucleotide fragment of the hugA gene was selected as the target for the CPA assay primers, as this gene is highly conserved in $P$. shigelloides strains (25). Primer specificity was determined by subjecting 33 non- $P$. shigelloides strains (causing similar clinical syndromes to $P$. shigelloides) to the $P$. shigelloides hugA CPA assay, revealing $100 \%$ specificity of the CPA assay for $P$. shigelloides. Positive amplification was completed by visual inspection, and no positive reactions were observed in the assays of non- $P$. shigelloides strains. The results of the present study suggested that the CPA assay for the detection of the gene that encodes the HugA outer membrane receptor required for heme iron utilization by $P$. shigelloides may be a reliable method to detect $P$. shigelloides. This procedure combined with an enrichment step allows $P$. shigelloides detection in clinical and environment specimens.

To the best of our knowledge, the present study is the first to use CPA technology to detect $P$. shigelloides in clinical and environmental specimens. The $P$. shigelloides hugA CPA method was 100-fold more sensitive than conventional PCR methods, detecting as little as $200 \mathrm{fg}$ DNA per reaction. Several previous studies have also demonstrated that CPA has greater sensitivity than PCR for pathogen detection (17,29,31-34). Thus, the $P$. shigelloides hugA CPA assay is more appropriate than PCR for simple, rapid and sensitive detection of $P$. shigelloides.

To evaluate the practical application of the $P$. shigelloides hugA CPA assay for detection of $P$. shigelloides in clinical samples, 100 specimens of clinical and environmental origins were analysed using conventional culture-based detection detection, PCR, and the P. shigelloides hugA CPA assay. The $P$. shigelloides hugA CPA assay exhibited greater $P$. shigelloides detection capability than PCR, which was supported by several previous studies (17,29,31-34). The conventional PCR method also led to false negative results that were detected by the $P$. shigelloides hugA CPA assay; 3 stool specimens and 1 water sample were positive by culture and CPA, but PCR did not detect $P$. shigelloides in these samples. The reduced detection rate of PCR may be due to copy numbers of the $P$. shigelloides template that were less than the LoD, or the presence of PCR-specific inhibitors that may have affected the reaction sensitivity.

In conclusion, to the best of our knowledge, this is the first report of a CPA assay for the rapid detection of $P$. shigelloides. Compared with currently existing PCR methods, the $P$. shigelloides hugA CPA assay offers the advantages of improved sensitivity, rapidity, detection capability and ease of operation. In general, the CPA assay provides increased flexibility for clinical applications, and the isothermal amplification feature provides a potential method for the simple and rapid detection of $P$. shigelloides in basic clinical and field laboratories with limited resources.

\section{Acknowledgements}

This work was supported by the Mega Project of Research on The Prevention and Control of HIV/AIDS, Viral Hepatitis Infectious Diseases (grant nos. 2011ZX10004-001 and 2013ZX10004-101) from the Ministry of Science and Technology and the State Key Laboratory of Infectious Disease Prevention and Control, Chinese Center for Disease Control and Prevention (grant no. 2015SKLID507).

\section{References}

1. Garrity GM, Bell JA and Lilburn TG: Taxonomic outline of the procaryotes. Bergey's Manual of Systematic Bacteriology, 2nd edition. Release 4.0 http://141.150. 157, 2003.80/bergeysoutline/main.html.

2. Bodhidatta L, McDaniel P, Sornsakrin S, Srijan A, Serichantalergs $\mathrm{O}$ and Mason CJ: Case-control study of diarrheal disease etiology in a remote rural area in Western Thailand. Am J Trop Med Hyg 83: 1106-1109, 2010.

3. Krovacek K, Eriksson LM, González-Rey C, Rosinsky J and Ciznar I: Isolation, biochemical and serological characterisation of Plesiomonas shigelloides from freshwater in Northern Europe. Comp Immunol Microbiol Infect Dis 23: 45-51, 2000.

4. Reinhardt JF and George WL: Plesiomonas shigelloides-associated diarrhea. Jama 253: 3294-3295, 1985.

5. Aquilini E, Merino S, Regué M and Tomás JM: Genomic and proteomic studies on Plesiomonas shigelloides lipopolysaccharide core biosynthesis. J Bacteriol 196: 556-567, 2014.

6. González-Rey C, Svenson SB, Bravo L, Rosinsky J, Ciznar I and Krovacek K: Specific detection of Plesiomonas shigelloides isolated from aquatic environments, animals and human diarrhoeal cases by PCR based on 23S rRNA gene. FEMS Immunol Med Microbiol 29: 107-113, 2000.

7. Chen X, Chen Y, Yang Q, Kong H, Yu F, Han D, Zheng S, Cui D and Li L: Plesiomonas shigelloides infection in Southeast China. PloS One 8: e77877, 2013.

8. Schneider F, Lang N, Reibke R, Michaely HJ, Hiddemann W and Ostermann H: Plesiomonas shigelloides pneumonia. Med Mal Infect 39: 397-400, 2009.

9. Ozdemir O,SariS, Terzioglu S and Zenciroglu A: Plesiomonas shigelloides sepsis and meningoencephalitis in a surviving neonate. J Microbiol Immunol Infect 43: 344-346, 2010.

10. Auxiliadora-Martins M, Bellissimo-Rodrigues F, Viana JM, Teixeira GC, Nicolini EA, Cordeiro KS, Colozza G, Martinez R, Martins-Filho OA and Basile-Filho A: Septic shock caused by Plesiomonas shigelloides in a patient with sickle beta-zero thalassemia. Heart Lung 39: 335-339, 2010.

11. Chan SS, Ng KC, Lyon DJ, Cheung WL, Cheng AF and Rainer TH: Acute bacterial gastroenteritis: A study of adult patients with positive stool cultures treated in the emergency department. Emerg Med J 20: 335-338, 2003.

12. Xia FQ, Liu PN and Zhou YH: Meningoencephalitis caused by Plesiomonas shigelloides in a Chinese neonate: Case report and literature review. Ital J Pediatr 41: 3, 2015.

13. Pence MA: The brief case: Wound infection with Plesiomonas shigelloides following a freshwater injury. J Clin Microbiol 54: 1180-1182, 2016.

14. Meng S, Xu J, Xiong Y and Ye C: Rapid and sensitive detection of Plesiomonas shigelloides by loop-mediated isothermal amplification of the hugA gene. PloS One 7: e41978, 2012.

15. Mori Y and Notomi T: Loop-mediated isothermal amplification (LAMP): A rapid, accurate and cost-effective diagnostic method for infectious diseases. J Infect Chemother 15: 62-69, 2009.

16. Parida M, Sannarangaiah S, Dash PK, Rao PV and Morita K: Loop mediated isothermal amplification (LAMP): A new generation of innovative gene amplification techniquperspectives in clinical diagnosis of infectious diseases. Rev Med Virol 18: 407-421, 2008. 
17. Wang Y, Wang Y, Ma A, Li D and Ye C: Rapid and sensitive detection of Listeria monocytogenes by cross-priming amplification of lmo0733 gene. FEMS Microbiol Lett: Oct 1, 2014 (Epub ahead of print).

18. Yang HL, Huang J, Yang B, Liu F and Zhang QL: The establishment and application of isothermal cross-priming amplification techniques in detecting penaeid shrimp white spot syndrome virus. Lett Appl Microbiol 59: 200-206, 2014.

19. Zhang F, Wang L, Fan K, Wu J and Ying Y: The detection of T-Nos, a genetic element present in GMOs, by cross-priming isothermal amplification with real-time fluorescence. Anal Bioanal Chem 406: 3069-3078, 2014.

20. Bai Z, Xie H, You Q, Pickerill S, Zhang Y, Li T, Geng J, Hu L, Shan $\mathrm{H}$ and Di B: Isothermal cross-priming amplification implementation study. Lett Appl Microbiol 60: 205-209, 2015.

21. Janda JM and Abbott SL: Expression of hemolytic activity by Plesiomonas shigelloides. J Clin Microbiol 31: 1206-1208, 1993.

22. Santos JA, González CJ, López TM, Otero A and García-López ML: Hemolytic and elastolytic activities influenced by iron in Plesiomonas shigelloides. J Food Prot 62: 1475-1477, 1999.

23. Villarreal DM, Phillips CL, Kelley AM, Villarreal S, Villaloboz A, Hernandez P, Olson JS and Henderson DP: Enhancement of recombinant hemoglobin production in Escherichia coli BL21(DE3) containing the Plesiomonas shigelloides heme transport system. Appl Environ Microbiol 74: 5854-5856, 2008.

24. Oldham AL, Wood TA and Henderson DP: Plesiomonas shigelloides hugZ encodes an iron-regulated heme binding protein required for heme iron utilization. Can J Microbiol 54: 97-102, 2008

25. Herrera FC, Santos JA, Otero A and García-López ML: Occurrence of Plesiomonas shigelloides in displayed portions of saltwater fish determined by a PCR assay based on the hugA gene. Int J Food Microbiol 108: 233-238, 2006.
26. Wandersman C and Stojiljkovic I: Bacterial heme sources: The role of heme, hemoprotein receptors and hemophores. Curr Opin Microbiol 3: 215-220, 2000

27. Xu G, Hu L, Zhong H, Wang H, Yusa S, Weiss TC, Romaniuk PJ, Pickerill S and You Q: Cross priming amplification: Mechanism and optimization for isothermal DNA amplification. Sci Rep 2: 246, 2012.

28. Okon E, Bishburg E, Ugras S, Chan T and Wang $\mathrm{H}$ : Clostridium perfringens meningitis, Plesiomonas shigelloides sepsis: A lethal combination. Am J Case Rep 14: 70-72, 2013.

29. Wozniakowski G, Niczyporuk JS, Samorek-Salamonowicz E and Gaweł A: The development and evaluation of cross-priming amplification for the detection of avian reovirus. J Appl Microbiol 118: 528-536, 2015

30. Fang R, Li X, Hu L, You Q, Li J, Wu J, Xu P, Zhong H, Luo Y, Mei J and Gao Q: Cross-priming amplification for rapid detection of Mycobacterium tuberculosis in sputum specimens. J Clin Microbiol 47: 845-847, 2009.

31. Zhang H, Feng S, Zhao Y, Wang S and Lu X: Detection of Yersinia enterocolitica in milk powders by cross-priming amplification combined with immunoblotting analysis. Int J Food Microbiol 214: 77-82, 2015.

32. Zhang X, Du XJ, Guan C, Li P, Zheng WJ and Wang S: Detection of Vibrio cholerae by isothermal cross-priming amplification combined with nucleic acid detection strip analysis. Mol Cell Probes 29: 208-214, 2015

33. Qiao B, Cui JY, Sun L, Yang S and Zhao YL: Cross-priming amplification targeting the coagulase gene for rapid detection of coagulase-positive Staphylococci. J Appl Microbiol 119: 188-195, 2015.

34. Ke Y, Wang Y, Wang Z, Du X, Huang L and Chen Z: Sensitive and rapid detection of blaNDM-1 in clinical samples by isothermal cross-priming amplification. J Microbiol Methods 95: 215-217, 2013. 